PREPARED FOR THE U.S. DEPARTMENT OF ENERGY, UNDER CONTRACT DE-AC02-76CH03073

PPPL-3838

PPPL-3838

UC-70

Electrostatic Probe with Shielded Probe Insulator Tube for Low Disturbing Plasma Measurements in Hall Thrusters

by

D. Staack, Y. Raitses, and N.J. Fisch

July 2003

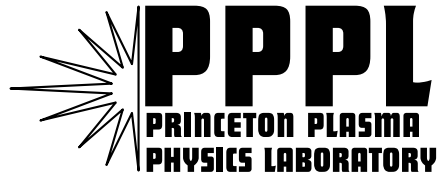

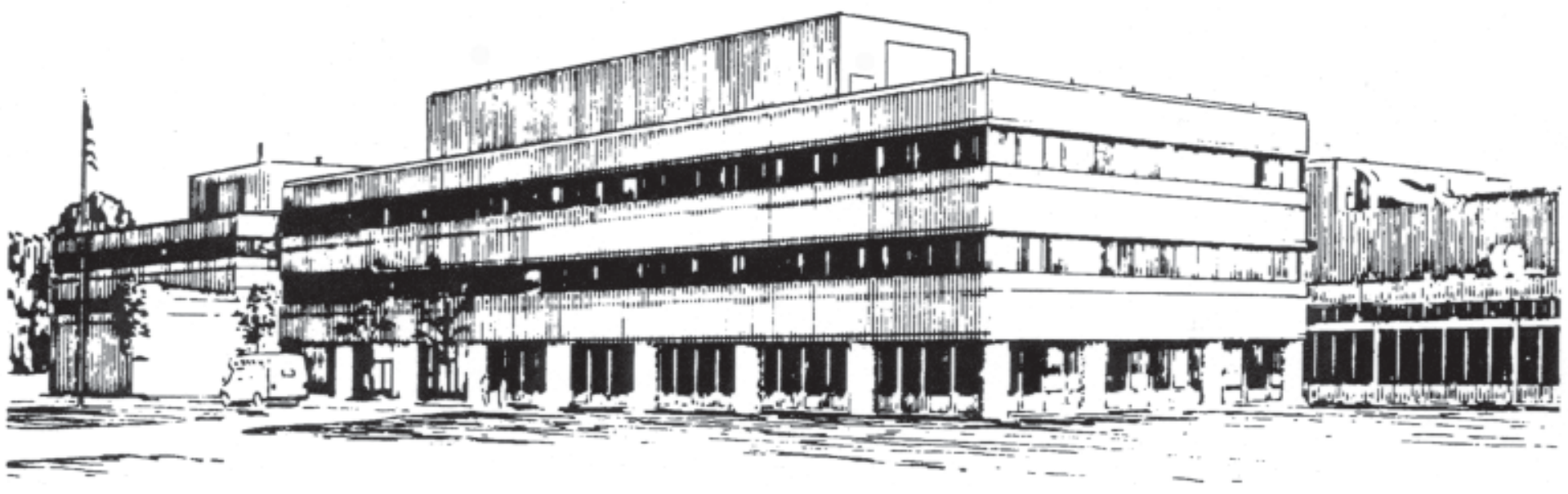

PRINCETON PLASMA PHYSICS LABORATORY PRINCETON UNIVERSITY, PRINCETON, NEW JERSEY 


\section{PPPL Reports Disclaimer}

This report was prepared as an account of work sponsored by an agency of the United States Government. Neither the United States Government nor any agency thereof, nor any of their employees, makes any warranty, express or implied, or assumes any legal liability or responsibility for the accuracy, completeness, or usefulness of any information, apparatus, product, or process disclosed, or represents that its use would not infringe privately owned rights. Reference herein to any specific commercial product, process, or service by trade name, trademark, manufacturer, or otherwise, does not necessarily constitute or imply its endorsement, recommendation, or favoring by the United States Government or any agency thereof. The views and opinions of authors expressed herein do not necessarily state or reflect those of the United States Government or any agency thereof.

\section{Availability}

This report is posted on the U.S. Department of Energy's Princeton Plasma Physics Laboratory Publications and Reports web site in Fiscal Year 2003. The home page for PPPL Reports and Publications is: http://www.pppl.gov/pub_report/

DOE and DOE Contractors can obtain copies of this report from:

U.S. Department of Energy

Office of Scientific and Technical Information

DOE Technical Information Services (DTIS)

P.O. Box 62

Oak Ridge, TN 37831

Telephone: (865) 576-8401

Fax: (865) 576-5728

Email: reports@adonis.osti.gov

This report is available to the general public from:

National Technical Information Service

U.S. Department of Commerce

5285 Port Royal Road

Springfield, VA 22161

Telephone: $1-800-553-6847$ or

(703) $605-6000$

Fax: (703) 321-8547

Internet: http://www.ntis.gov/ordering.htm 


\title{
Electrostatic probe with shielded probe insulator tube for low disturbing plasma measurements in Hall Thrusters
}

\author{
D. Staack, Y. Raitses and N. J. Fisch \\ Princeton Plasma Physics Laboratory, Princeton, NJ 08543
}

\section{ABSTRACT}

Electrostatic probes are widely used to measure spatial plasma parameters of the quasineutral plasma in Hall thrusters and similar $\mathrm{E} \times \mathrm{B}$ electric discharge devices. Significant perturbations of the plasma, induced by such probes, can mask the actual physics involved in operation of these devices. In Hall thrusters, probe induced perturbations can produce changes in the discharge current and plasma parameters on the order of their steady state values. These perturbations, are explored by varying the material, penetration distance and residence time of various probe designs. A possible cause of these perturbations appears to be the secondary electron emission, induced by energetic plasma electrons, from insulator ceramic tubes in which the probe wire is inserted. A new probe in which a low secondary electron emission material, such as metal, shields the probe ceramic tube, is shown to function without producing such large perturbations. A segmentation of this shield further prevents probe-induced perturbations, by not shortening the plasma through the conductive shield. In a set of experiments with a segmented shield probe, the thruster was operated in the input power range of 500-2.5 $\mathrm{kW}$ and discharge voltages of $200-500 \mathrm{~V}$, while the probe induced perturbations of the discharge current were below $4 \%$ of its steady state value in the region in which $90 \%$ of the voltage drop takes place. 


\section{INTRODUCTION}

A conventional Hall thruster is a crossed field electric discharge device with a radial magnetic field and axial electric field applied in a coaxial channel [1]. This magnetic field impedes electrons from their motion towards the anode leading to the establishment of a significant axial electric field in a quasi-neutral plasma. The ions, resulting from electron impact ionization of neutral gas atoms, are electro-statically accelerated through the azimuthally rotating cloud of magnetized electrons towards the channel exit. The thrust is produced as the reaction force to this acceleration. It is transferred through the magnetic field surfaces created by the azimuthally rotating electrons, which are essentially equipotential, to the magnetic circuit of the thruster.

Probe measurements are a vital means to understanding the physical process involved in operation of Hall thrusters. Electrostatic probes placed near the thruster channel walls have been successfully used in many studies (See, for example, Refs. 2 and 3). However, near-wall probes cannot give precise information on the plasma bulk since the plasma parameters are not radially uniform between the walls [4], [5]. On the other hand, introducing probes into the bulk plasma in particular in the acceleration and ionization regions causes significant perturbations to the Hall thruster discharge. For example, in references 4, 6 and 7, the discharge current increased by as much as $50-100 \%$ of its steady state value when the probe was moved into these regions. In reference 8 it was shown that most of these perturbations were produced by the ceramic tube of the probe and not by the probe wire.

The energy absorbed by the probe from the plasma can cause the probe to heat up, leading to its ablation and eventually to destruction. On the other hand, the resulting plasma and 
power losses to the probe surface may decrease plasma density and temperatures thereby altering the overall discharge characteristics almost instantaneously. In glow discharges, because the electron temperature and plasma densities are relatively low, these effects may be too small to appreciably change the discharge or damage the probe. In fusion related devices, high plasma density and temperatures can cause significant heating of the probe. In order to prevent probe destruction, fast positioning systems and in some cases graphite shielding of the probes have been successfully applied in studies of the edge physics in these devices [9]. Since the power and plasma losses to the probe are small compared to the power of the entire fusion device, the probe effect on the plasma is less noticeable.

In Hall thrusters, the relatively high electron temperatures of about $20-30 \mathrm{eV}$ and relatively low total power on the order of $1 \mathrm{~kW}$ combine to make both the probe's effect on the plasma and the plasma's effect on the probe significant. Fast movable probes were successfully used in a $140 \mathrm{~mm}$ diameter Hall thruster to avoid probe ceramic tube ablation, and, thus, probeinduced perturbations. Perturbations in their experiments were only $10 \%$ of the discharge current at $1.5 \mathrm{~kW}$ thruster input power [10]. However, the absolute amplitude of the discharge current perturbations in that thruster is comparable with those for a $90 \mathrm{~mm}$ Hall thruster operating at 0.4 $\mathrm{kW}$ used in a different setup with a similar fast movable probe setup [4]. Since the power densities of both thrusters of Ref 10 and 4 and the probe sizes are comparable, for the smaller thruster the relative fraction of probe-induced perturbations is greater.

Although, probe tube ablation, which is a consequence of the power lost to the tube integrated over the probe's exposure time, can be avoided by reducing the probe residence time in the plasma. The interaction between the plasma and probe tube also depends on the plasmaprobe wall sheath. The sheath is established in a shorter period of time $\left(\tau_{\text {sheath }} \sim 10^{-5}-10^{-6} \mathrm{sec}\right)$ than 
the residence time of the probe $\left(\tau_{\text {probe }} \sim 10^{-1}-10^{-2} \mathrm{sec}\right)$. The sheath and steady state electron flux to the probe tube is determined by the electron temperature and material properties of the wall, namely, secondary electron emission (SEE).

In the present work we study the effect of the probe tube material on the plasma in a Hall thrusters using a fast movable probe setup. We employ probe tubes made from different materials in diagnosing the $90 \mathrm{~mm}$ laboratory thruster. We show that a metal probe shield can substantially reduce the absolute amplitude of probe induced perturbations of the plasma, and relate this amplitude reduction to the lower secondary electron emission of the metal probe shield compared to the emission from ceramic tubes. Further results on a $123 \mathrm{~mm}$ laboratory thruster confirm these results at similar and larger thruster input powers. Also, reduction of the probeinduced perturbations is achieved by segmenting the shield of the probe, an affect which appears to be related to less shorting of the plasma through the conducting probe shield.

\section{EXPERIMENTAL SETUP AND PROCEDURE}

\section{$90 \mathrm{~mm}$ Thruster}

The $90 \mathrm{~mm}$ laboratory Hall thruster and test facility used in this study (Fig. 1) has been described elsewhere [11]. Electrostatic probes in single, and emissive configurations were mounted on a high-speed axial positioning system, which inserts and removes the probe from the thruster at $10 \mathrm{~m} / \mathrm{s}^{2}$ acceleration and velocities up to $0.5 \mathrm{~m} / \mathrm{s}$. The emissive probe was used to measure the plasma potential, and, together with the non-emissive probe which measures the floating potential, to estimate the electron temperature. The probe consists of a high purity alumina tube that insulates the probe wire. Approximately $30 \mathrm{~mm}$ of the probe tube is exposed to the plasma and passes through a significant electric field while the probe is inserted into the 
thruster channel. In a different set of experiments, we found that the alumina insulating tube alone without the wire caused most of the perturbations induced by the probe [8]. Therefore, in all the experiments described below for the $90 \mathrm{~mm}$ thruster, ceramic insulator tubes without wires were used. For Hall thrusters, the maximum electron temperature is typically $20-30 \mathrm{eV}$, which is near the first SEE threshold for ceramic materials [1]. Hence, similar to the interaction of the plasma with the ceramic channel walls of the thruster [1], the interaction of the plasma with the ceramic probe walls can have a significant effect on the electron transport across the magnetic field and on the electron temperature. In order to study the effect of the probe tube material, we used a tube made from quartz in addition to the alumina insulating probe tube, which is commonly used in Hall thruster probe measurements. Moreover, a rod made from tungsten, which has lower SEE than alumina and quartz, was used instead of the probe tube.

The perturbations where characterized by changes in the measured discharge current during the insertion of the probe. The effect of these perturbations were studied by measuring the changes in the floating potentials of three fixed Langmuir probes at different azimuthal locations along the outer channel wall near the thruster exit (Fig. 1). The Langmuir probes potential were measured relative to ground, as was the cathode voltage. Typically, the cathode to ground potential was constant during probe insertion, but to take into account small changes in the cathode to ground potential the changes in Langmuir probe potential presented in this paper are relative to the cathode. The floating potential of the stationary Langmuir probes, $\phi_{\mathrm{f}}$, is related to the plasma potential, $\phi_{\mathrm{p}}$, and the electron temperature $\mathrm{T}_{\mathrm{e}}$ by:

$$
\phi_{f}=\phi_{p}-\left(k T_{e} / e\right)\left(\ln \left(\sqrt{M_{i} / 2 \pi m_{e}}\right)+e^{-\frac{1}{2}}\right),
$$

where $\mathrm{k}$ is the Boltzmann constant, $\mathrm{e}$ is the elementary charge, $\mathrm{M}_{\mathrm{i}}$ is the ion mass, and $\mathrm{m}_{\mathrm{e}}$ is the electron mass [12]. The exp(-1/2) accounts for the presheath potential drop. 


\section{$123 \mathrm{~mm}$ Thruster}

The $123 \mathrm{~mm}$ laboratory Hall thruster (Fig. 2) was operated in an upgraded version of the test facility used in the studies on the $90 \mathrm{~mm}$ thruster, the details of the upgrade which included cryogenic pumps, a larger thruster, and expanded diagnostics are described elsewhere [13]. An upgraded probe insertion system was used as well. The diagnostic probe is mounted on a highacceleration axial positioning system that in turn is mounted on a low speed axial and radial positioning system; see schematic Fig. 3. The high acceleration axial motion is produced by a $\mathrm{H} 2 \mathrm{~W}$ linear motor used at a maximum speed of $1.5 \mathrm{~m} / \mathrm{s}$ and a maximum acceleration of approximately $10 \mathrm{~g}\left(100 \mathrm{~m} / \mathrm{s}^{2}\right)$. The axial position is controlled in closed loop by a Galil DMC1800 motion controller at a loop frequency of $8 \mathrm{kHz}$ using position information measured with an optical encoder at a resolution of $10 \mu \mathrm{m}$. Two relatively slow Velmex linear gear motors provide radial and axial positioning of the $\mathrm{H} 2 \mathrm{~W}$ system with their position measured by a $5 \mu \mathrm{m}$ optical encoder. The radial Velmex is used to change the radial position of probe insertion, and the axial Velmex is used to hide the positioning system from the thruster's plume when the system is not in use. Bearing supports parallel to the Velmexes are used to balance the large torques produced by the cantilevered load of the $\mathrm{H} 2 \mathrm{~W}$ system and remove play in the system. The probe is mounted to a probe arm that is dielectrically isolated from ground and mounted on the positioning system through a Newport 3-axis stage, which adjusts the probes pitch, yaw, and height relative to the thruster.

A set of azimuthally located fixed Langmuir probes similar to those on the $90 \mathrm{~mm}$ thruster were also used to monitor disturbances. The $123 \mathrm{~mm}$ thruster was operated at the same voltage, $250 \mathrm{~V}$, as the $90 \mathrm{~mm}$ thruster and at a mass flow rate set to $3.2 \mathrm{mg} / \mathrm{s}$ so that the input power and 
flow rate divided by the thruster cross section area was the same for the two thrusters. Three probe designs were tested in the $123 \mathrm{~mm}$ thruster. First, an alumina tube similar to that from the $90 \mathrm{~mm}$ thruster experiments was tested. Second, an alumina tube shielded by a thin walled molybdenum tube was tested in order to have a low SEE material exposed to the plasma as in the case of the tungsten rod from the $90 \mathrm{~mm}$ tests but also to be functional as a probe wire insulator. Third, because shorting the plasma through the conducting shield was thought to affect changes in the discharge [14], two probes with a segmented shield on the alumina tube to achieve the effect of a non-conductive low SEE shield were tested. A segmented tungsten probe (Fig. 4a) was manufactured by plasma spray coating tungsten onto the alumina tube and then machining away rings of the tungsten to create the desired segmentation. A segmented graphite probe (Fig. 4b) was more simply manufactured by cementing short graphite rings to the alumina tube.

\section{EXPERIMENTAL RESULTS AND DISCUSSION}

Figure 5a shows a typical measurement of the discharge current for a single insertion while inserting an unshielded alumina insulated probe into the $90 \mathrm{~mm}$ thruster. To indicate where these disturbances are relative to the acceleration and ionization zones of the thruster, Figure $5 \mathrm{~b}$ shows the electric field, estimated electron temperature and normalized magnetic field. These quantities are obtained from an analysis of the emissive probe and cold probe floating potentials, by averaging over multiple insertions at the channel centerline, and from measurements of the radial magnetic field when the thruster was off. The discharge current begins increasing about $5 \mathrm{~mm}$ outside the thruster until about $5 \mathrm{~mm}$ inside the thruster, where large amplitude oscillations begin. It is possible to divide the effect of the probe on the discharge current perturbation into 
two phases, the initial, growing phase where the discharge current increases and the oscillatory phase where the discharge current oscillates. The oscillations are in the range of 15 to $20 \mathrm{kHz}$ for the alumina and tungsten probe, and are also visible on the stationary probes floating potential. Though the oscillations have not been fully characterized, we note that that the oscillations occur when the probe crosses the boundary between the acceleration region and ionization region. That boundary is essentially at the maximum in electron temperature. These characteristics suggest that these oscillation are a breathing-ionization instability [15], possibly induced by the increased ion and electron losses due to the presence of the probe in that region.

The disturbances in discharge current were repeatable over multiple probe insertions within $5 \%$ as functions of the position of the probe tip. Showing the dependence on the position of the probe, and not on the duration of probe insertion into the plasma, was arranged by changing the velocity and acceleration of the probe insertions and by stopping the probe inside the thruster for a short amount of time before removing it. The correlation between the probe position and the increase in discharge current, as opposed to the residence time of the probe in the thruster channel, indicates that these probe-induced perturbations of the plasma are most probably not due to ablation of the probe ceramic tube. Furthermore, because of a typically short residence time of the probe inside the thruster, less than $100 \mathrm{msec}$, and in spite of significant induced perturbations of the discharge, no visible recrystalization of the probe tube due to melting and solidifying were found in post run examinations through all the described experiments. In parallel experiments, probe ablation directed towards the azimuthal electron flux, similar to that of ref. 10, was found for the alumina probe, but only after residence times inside the thruster greater than one second. For the tungsten probe no ablation was visible after 15 seconds. 
Fig. 6 shows the DC (low pass filtered at $500 \mathrm{~Hz}$ ) component of the discharge current as a function of the position of the end of the probe tube for the alumina, quartz, and tungsten probe insertions in the $90 \mathrm{~mm}$ thruster. As seen in Fig. 6, the increases in the discharge current caused by the presence of the quartz and alumina tubes are substantially greater than for the floating tungsten rod. Looking at the changes in the stationary Langmuir probe potentials (Fig. 7), in the case of the ceramic tubes, we see the perturbations are larger and azimuthally localized in the vicinity of the probe immersion, whereas in the case of the tungsten rod, the perturbations are nearly azimuthally symmetric. A possible explanation of these results is as follows. In the presence of secondary electron emission, the sheath potential between the plasma and movable probe is described as:

$$
\Delta \phi=\left(k T_{e} / e\right) \ln \left((1-\gamma) \sqrt{M_{i} / 2 \pi m_{e}}\right),
$$

where $\gamma$ is the SEE coefficient. Since for quartz and alumina ceramic probe materials, the SEE reaches the first threshold at $\mathrm{T}_{\mathrm{e}} \sim 20-30 \mathrm{eV}$ (typical of the hall thruster). Thus the sheath potential becomes smaller, allowing more plasma bulk electrons to reach the tube wall. The probe is a sink for high-energy electrons [16] and contributes to a decrease in the electron temperature relative to the plasma without the probe. The resulting lower energy secondary electrons from the probe wall reduce the plasma bulk electron temperature and may increase the plasma density at least in the vicinity of the probe, but probably not in the entire channel as the disturbance measured by stationary probes is non-uniform in the aziumthal direction. If so, the obtained results can be interpreted as a local decrease of the electron temperature of about $5 \mathrm{eV}$.

For the tungsten rod, the secondary electron emission is significantly lower than for the ceramic tubes at the same energies of the primary electrons from the plasma. Therefore, the floating potential disturbance caused by the tungsten rod is significantly smaller. The measured 
azimuthal symmetry of this disturbance, assuming equipotential magnetic surfaces of the E $\times B$ discharge [1], suggests that this disturbance is related to changes in the plasma potential rather than to changes in the electron temperature. These changes may be caused by a shorting of the plasma through the conductive rod [11]. The floating tungsten rod is at constant potential in a strong electric field, the high potential end of the rod will have a more negative sheath potential and collect an excess of ions and the low potential end will have a less negative (or possibly positive) sheath potential and collect an excess of electrons. The excess of electrons on the negative end of the rod will flow through the rod to neutralize the excess of ions at the positive end of the rod. Current will thus pass through the rod, shorting the plasma and causing a decrease in the electric field along the length of the conducting rod. The segmented tungsten and graphite probes were designed to prevent perturbations caused by the shorting of the plasma since the conducting probe shield is discontinuous. Each of the shield segments floats at a different potential, and the current through each segment is small since the segment is short in length and the collection area is smaller.

Figures 8 and 9 show the discharge current and stationary probes perturbations during movable probe insertion for the $123 \mathrm{~mm}$ Hall Thruster operating at $250 \mathrm{~V}$ discharge voltage and 2.8 A discharge current for the alumina tube, molybdenum shielded alumina tube, and segmented tungsten shielded alumina tube. Similar to the $90 \mathrm{~mm}$ thruster the discharge current perturbations are significant decreased by shielding the alumina from the plasma. For the alumina probe the increase in discharge is significant outside the thruster. The increases caused by the molybdenum and segmented tungsten probes are much smaller and only about $2 \%$ of the discharge current. Discharge current oscillations greater than 0.3 amps in amplitude occurred for all types of probes beginning approximately $6 \mathrm{~mm}$ inside the channel. The amplitude of the oscillations was 
sensitive to magnetic field and magnetic fields could be found with less than $5 \%$ disturbances in the ionization region. This suggests there may be an optimal magnetic field with respect to small probe induced disturbances; however, it is not necessarily the optimum magnetic field with respect to thruster performance.

For the high SEE alumina tube, the Langmuir probe disturbances were larger and generally localized, again indicating a change in electron temperature. The changes in the stationary probe floating potential for the segmented tungsten probe were slightly smaller than for the molybdenum tube. The increase in discharge current for the two probes is approximately the same. An increase in discharge current around $0.7 \%$, (on the order of the disturbances measured), simply due to the additional surface of the probe can be expected by comparing the diameter of the probe $(1.4 \mathrm{~mm})$ to the diameters of the coaxial thruster (123 mm OD, $73 \mathrm{~mm}$ ID). Some of the small changes in Langmuir probe voltage may also be due to this increase in discharge current in addition to possible probe shield conductivity affects.

An addition benefit of shielding the insulator tube was that there was little concern for probe tube ablation. The positioning system was able to insert and remove the probe at $1 \mathrm{~m} / \mathrm{s}^{2}$ accelerations and $0.1 \mathrm{~m} / \mathrm{s}$ velocity without signs of ablation. These speeds are attainable with lower cost linear gear motors.

The measurements for the alumina tube in the $123 \mathrm{~mm}$ thruster were only repeatable for about 40 insertions, after which the alumina tube showed reduced perturbations. No such improvement was measured for several hundred insertions in the $90 \mathrm{~mm}$ thruster. The difference may be due to the larger flow rates for the larger thruster causing surface changes to the alumina tube. Since SEE is very sensitive to the surface material properties, coatings could reduce the 
SEE of the alumina thus reducing the perturbations caused by the probe. Indeed, post run examination of the probe showed a gray discoloration of the alumina surface.

The molybdenum and graphite ringlet shielded probes were also tested at larger flow rates and discharge voltage: $5.0 \mathrm{mg} / \mathrm{s}$, and a maximum $400 \mathrm{~V}$ and $600 \mathrm{~V}$ respectively for the two types of probes. Arcing to the molybdenum, which significantly affected the discharge, was visible at $400 \mathrm{~V}$. The molybdenum shield, because it is an equipotential and extends to outside the thruster, floats at a lower potential then the individual segments of the graphite shield. For the graphite ringlet shielded probe, when operating at $600 \mathrm{~V}$, occasional arcing was visible from the anode lead wires and from the probe and affected the discharge but the arcs were not functions of the probe position; with multiple insertions accurate profiles could be attained. These preliminary results indicate that in addition to benefits with respect to the changes in Langmuir probe voltage, the segmented probe shield may reduce such arcing when operating at high voltages. Figure 10 shows the discharge current and stationary probe perturbations as a function of the movable probe's position. The arcs are signified by dips and rises in the profiles and are more noticeable in the stationary probe voltage. The stationary probe voltage (fig 10b), unfiltered and sampled at $10 \mathrm{kHz}$, sharply changes at the edge of the ionization region similar to lower powers. The discharge current had many oscillatory components in this regime. Figure 10a is filtered at $500 \mathrm{~Hz}$ and due to instabilities the changes in discharge current are difficult to distinguish. An averaging over multiple insertions of the discharge current (rather than filtering which would remove sharp increased in the average value) shows the increase in discharge current to be less than $150 \mathrm{~mA}$ in the acceleration region and 0.4 Amps in the ionization region. The main conclusions to draw from these measurements are that, at high voltage (500V) and 2.4 $\mathrm{kW}$ power using the segmented probe design, measurements can be made internally with less 
than $4 \%$ disturbances in the acceleration region. Another conclusions to be drawn from Figure 10 is that the stationary probes provide a clearer picture of the probe-induced disturbances than just the discharge current alone.

\section{CONCLUSIONS}

Typically, large perturbations of the plasma in Hall thrusters, caused by introduction of electrostatic probes in the discharge channel, may be attributed to large secondary electron emission from probe insulator tube, which is usually made from ceramic materials. A lower secondary electron emission tungsten rod, molybdenum tube, graphite tube, or tungsten coated tube causes significantly smaller disturbances of the discharge current than quartz and alumina tubes. At higher operating voltages arcing to the shields may be attributed to its conductivity, though this might be avoided by segmentation of the metal shield. By shielding the alumina probe tube, the measurement range of reliable probe measurements has been increased to include the acceleration region inside the thruster. When the thruster is operating at $250 \mathrm{~V}$ discharge voltage and a mass flow rate of $3.2 \mathrm{mg} / \mathrm{s}$, perturbations in the acceleration region were less than $2 \%$ of the unperturbed discharge current. When operating as high as $500 \mathrm{~V}$ and $5 \mathrm{mg} / \mathrm{s}$, probe induced changes in discharge current in the acceleration region were less than $4 \%$ of the unperturbed discharge current. However, even while employing the segmented shielded probe significant perturbations still exist when introducing probes into the ionization region even if not in the acceleration region. Nevertheless, overall, a remarkable decrease in probe-induced perturbations is achieved with the new probe designs.

\section{ACKNOWLEDGEMENTS}


The authors are grateful to Tim Knowles from Energy Science Laboratories for providing us with the graphite ringlets and to George Rose for manufacturing of the tungsten shielded probes. This work was supported by grants from the U.S. Department of Energy under Contract No. DE-AC02-76-CHO-3073. 


\section{References}

${ }^{1}$ A. Morosov, and V. Savelyev "Fundamentals of Stationary Plamsa Thruster Theory", in Review of Plasma Physics, edited by B. Kadomtsev and V. Shafranov (Consultants Bureau, New York, 2000), Vol. 21.

${ }^{2}$ G. Guerrini, C. Michaut, A.N. Vesselovzorov, and M. Bacal, "Characterization of Plasma Inside the SPT-50 Channel by Electrostatic Probes”, IEPC paper 97-053, $25^{\text {th }}$ International Electric Propulsion Conference, Cleveland, Ohio, 14-28 August 1997.

${ }^{3}$ V. Kim, D. Grdlichko, V. Kozlov, A. Lazourenko, G. Popov and A. Skrylnikov, "Local Plasma Parameter Measurements by Near wall probes Inside the SPT Accelerating Channel Under Thruster Operation with Kr", AIAA Paper 2002-4108, 38th AIAA/ASME/SAE/ASEE Joint Propulsion Conference \& Exhibit, 7-10 July 2002.

${ }^{4}$ Raitses Y, Keidar M, Staack D, Fisch NJ, "Effects of segmented electrode in Hall current plasma thrusters", J. Appl. Phys. 92 (9): 4906-4911 November 2002,

${ }^{5}$ Haas, J.M., and Gallimore, A.D., "Internal Plasma Potential Profiles in a Laboratory-Model Hall Thruster," Physics of Plasmas, Vol. 8, No. 2, pp. 652-660, February 2001.

${ }^{6}$ E. Chesta, C. lam, N. Meezan, D. Schmidt, and M. Cappelli, “A Characterization of Plasma Fluctuations within a Hall Discharge”, IEEE Trans. Plasma Sci. 29, 582 (2001).

${ }^{7}$ R. Hoffer, A. Gallimore, "Recent Results from Internal and Very near Field Plasma Diagnostics of a High Specific Impulse Hall Thruster", IEPC paper 03-0037, the 28th International Electric Propulsion Conference, Toulouse, France, March 2003.

${ }^{8}$ D. Staack, Y. Raitses, and N. J. Fisch, "Investigation of Probe Induced Perturbations in a Hall Thruster", AIAA Pap. 02, 4174 (2002). 
${ }^{9}$ J.G. Watkins, J.Salmonson, R.Moyer, R. Doerner, R.Lehmer, L. Schmitz, D.N. Hill, “A fast scanning probe for DIII-D” Rev. Sci. Instrum. 63, 4728 (1992).

${ }^{10}$ J. M. Haas and A. D. Gallimore, "Development of a high-speed, reciprocating electrostatic probe system for Hall thruster interrogation”, Rev. of Sci. Instrum. 71, 4131 (2000).

${ }^{11}$ Y. Raitses, L.A. Dorf, A. Litvak, and N. J. Fisch, J. Appl. Phys. 89, 2040 (2001).

${ }^{12}$ Hershkowitz, N., "Theory of Electrostatic Probes", in Plasma Diagnostics, edited by O.

Auicello, D. Flam (Academic Press, NY, 1989). Alternate more modern reference than

Langmuir.

${ }^{13}$ Y. Raitses, D. Staack, A. Dunaevsky, L. Dorf and N. J. Fisch, "Measurements of Plasma Flow in a $2 \mathrm{~kW}$ Segmented Electrode Hall Thruster", IEPC paper 03-0139, the 28th International Electric Propulsion Conference, Toulouse, France, March 2003.

${ }^{14}$ D. Staack, Y. Raitses, and N. J. Fisch, "Control of Acceleration Region in Hall Thrusters“" IEPC paper 03-0273, Toulouse, France, March 2003.

${ }^{15}$ J.P. Boeuf and L. Garrigues, Journal of Applied Physics, Vol. 84, 1998.

${ }^{16}$ P. C. Stangeby, "Physics of Plasma-Wall Interactions in Controlled Fusion", in The Plasma Sheath, edited by D. E. Post and R. Behrisch, pp 41-95, Plenum Press, New York 1986. 


\section{Figures List}

Figure 1: PPPL 90mm Hall thruster with stationary probe and high-speed movable probe.

Figure 2: PPPL 123mm Hall thruster with stationary probe and high-speed movable probe.

Figure 3: Schematic of the high acceleration probe positioning system.

Figure 4: (a) Photograph and schematic cross section of segmented tungsten probe, and (b) photograph of segmented shield using graphite ringlets, dimensions in millimeters.

Figure 5: Typical discharge current (a), electric field, electron temperature, and normalized magnetic field (b) profiles during probe insertion for the $90 \mathrm{~mm}$ thruster operating at $250 \mathrm{~V}$ and $1.7 \mathrm{mg} / \mathrm{s}$. The thruster exit plane is at $46 \mathrm{~mm}$ from the anode.

Figure 6: Discharge current perturbations caused by quartz, tungsten, and alumina probes in the $90 \mathrm{~mm}$ thruster operating at $250 \mathrm{~V}$ and $1.7 \mathrm{mg} / \mathrm{s}$.

Figure 7: Changes in stationary probe voltages azimuthally (a) near and (b) opposite the point of insertion for the quartz, tungsten, and alumina probes for the $90 \mathrm{~mm}$ thruster operating at $250 \mathrm{~V}$ and $1.7 \mathrm{mg} / \mathrm{s}$.

Figure 8: Changes in discharge current caused by alumina, molybdenum shielded, and segmented tungsten shielded probes in the $123 \mathrm{~mm}$ thruster operating at $250 \mathrm{~V}$ and $3.2 \mathrm{mg} / \mathrm{s}$. Unperturbed discharge current was 2.8 amps.

Figure 9: Changes in stationary probe voltages azimuthally (a) near and (b) opposite the point of insertion from the molybdenum shielded, and segmented tungsten shielded probes in the $123 \mathrm{~mm}$ thruster operating at $250 \mathrm{~V}$ and $3.2 \mathrm{mg} / \mathrm{s}$.

Figure 10: Changes in discharge current (a) and stationary probe voltage near insertion (b) for the probe with segmented graphite shield operating at $500 \mathrm{~V}$ discharge voltage and $5.0 \mathrm{mg} / \mathrm{s}$ flow rate. Unperturbed discharge current was 4.7 amps. 


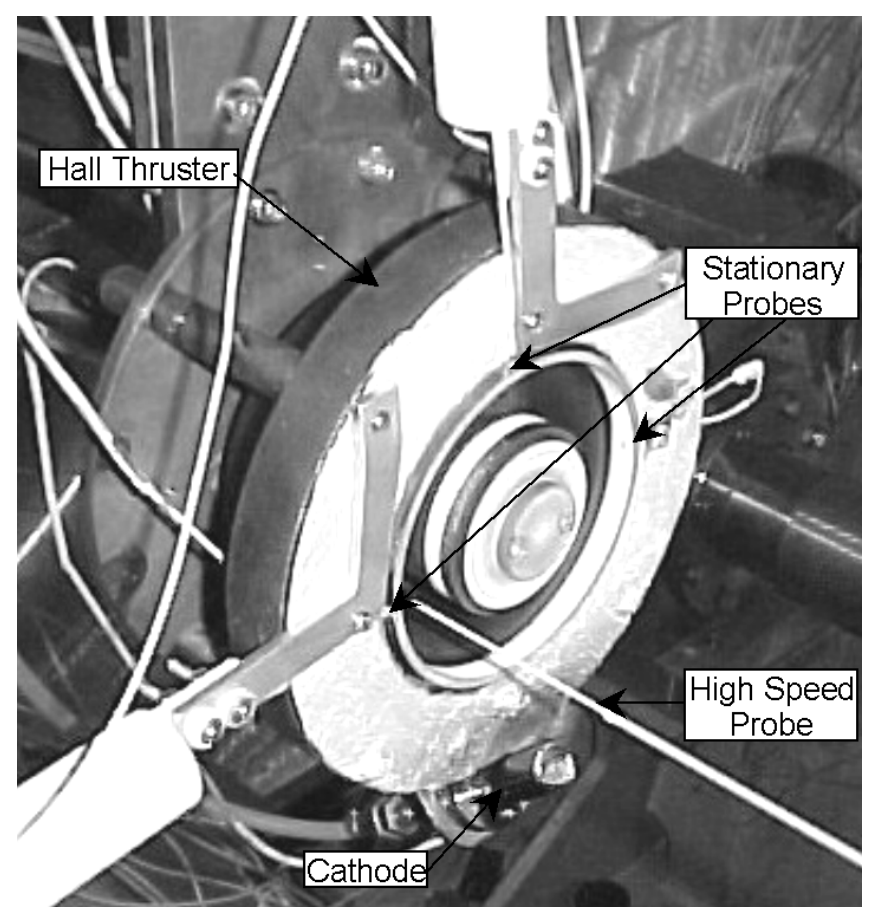

Figure 1 


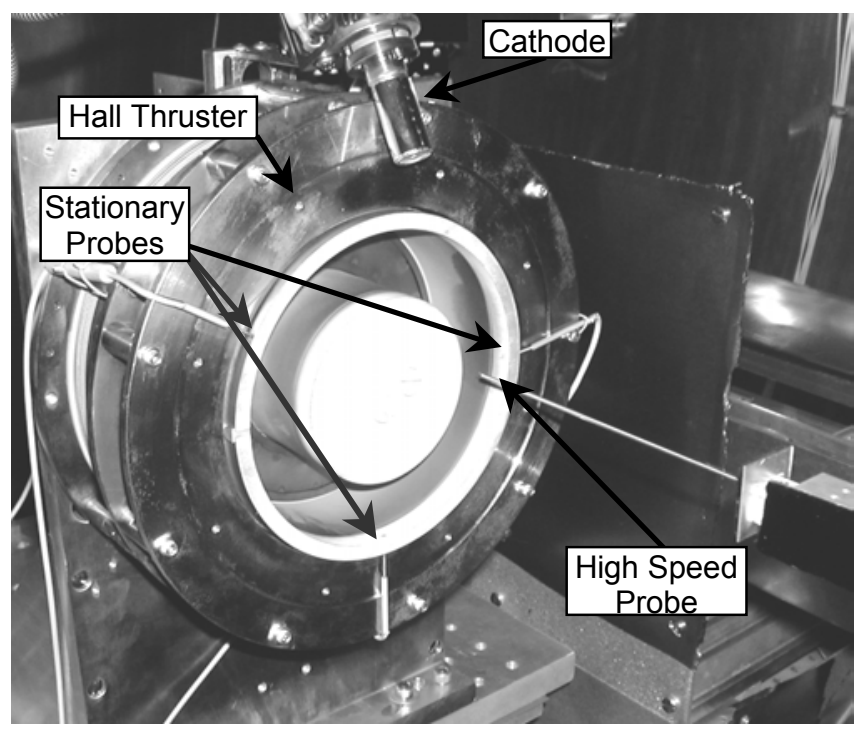

Figure 2 


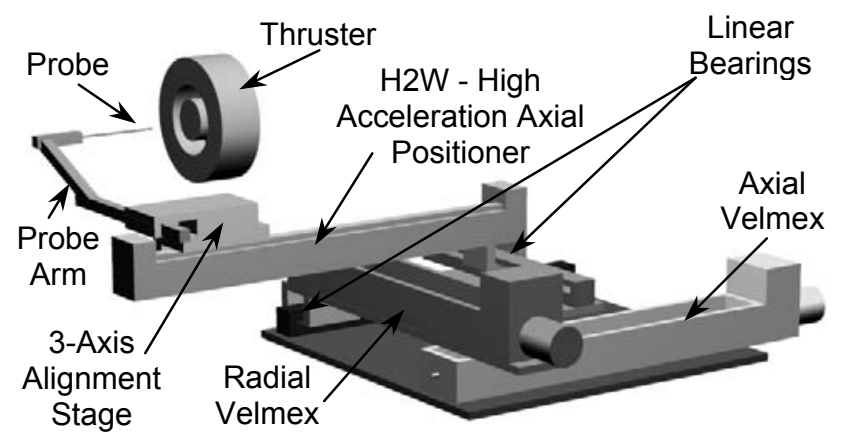

Figure 3 
(a)

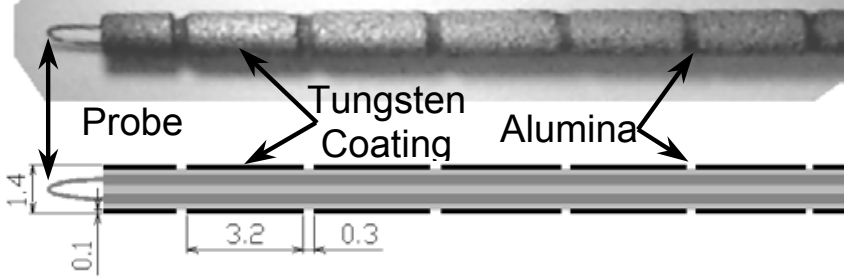

(b)

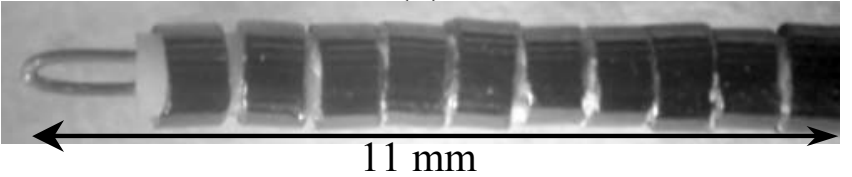

Figure 4 
(a)
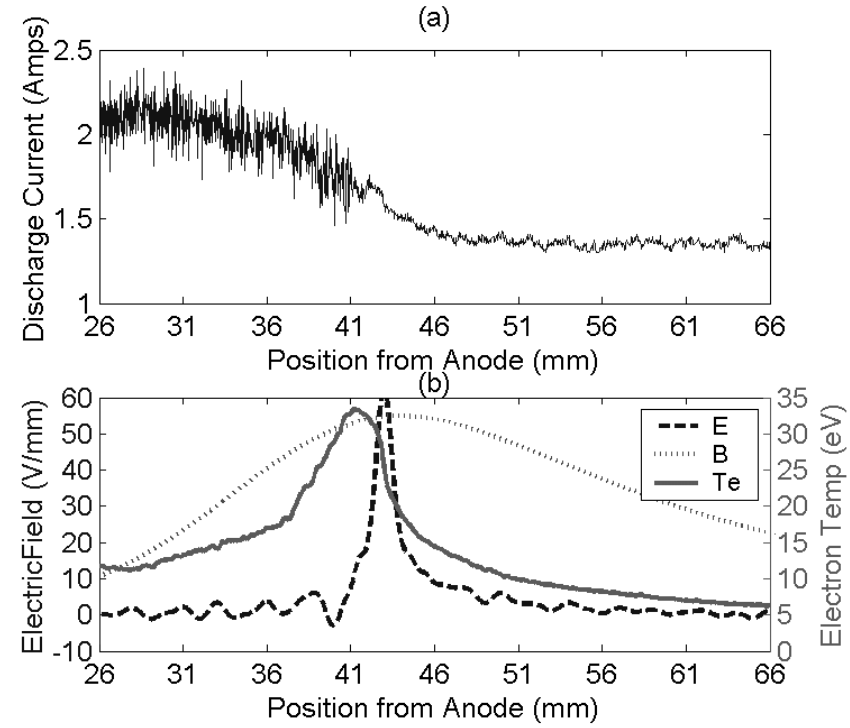

Figure 5 


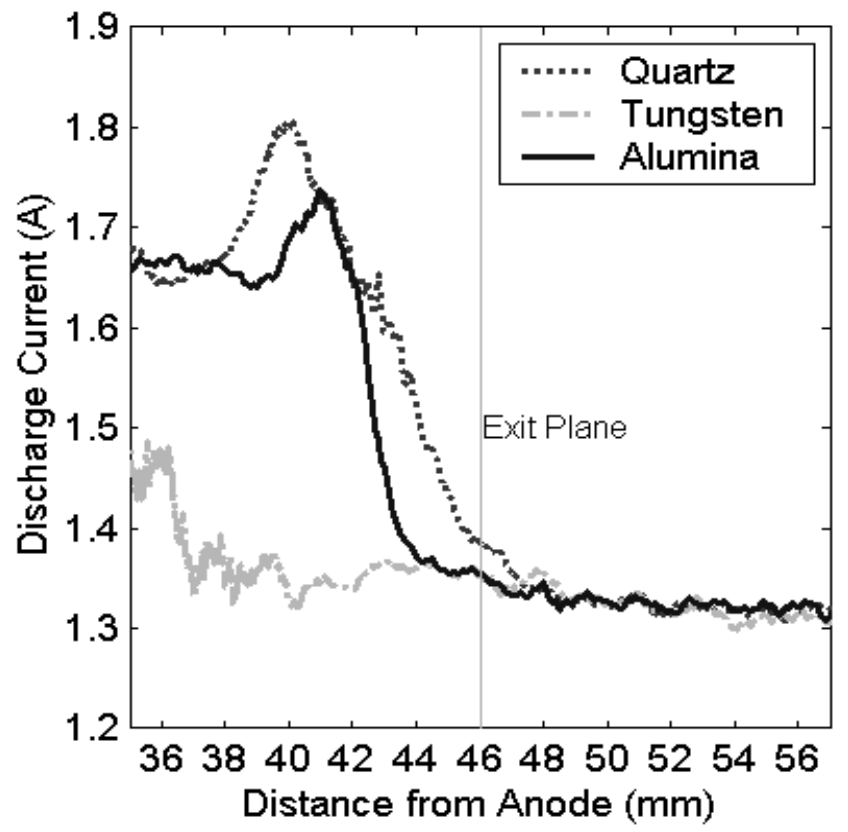

Figure 6 
(a) - Near Insertion
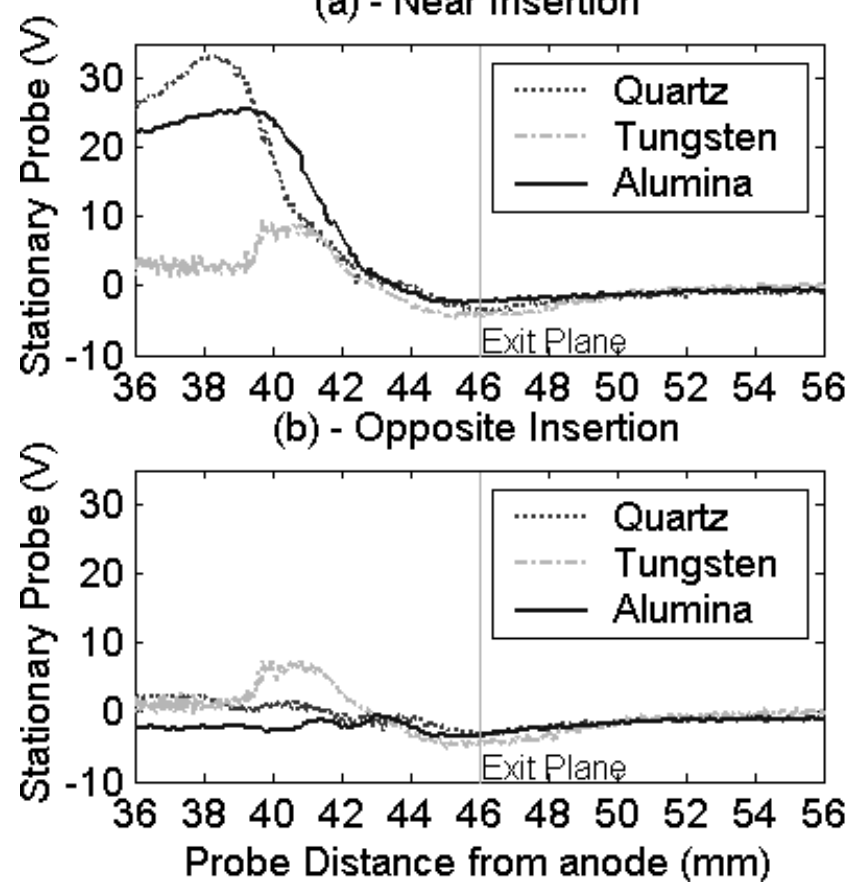

Figure 7 


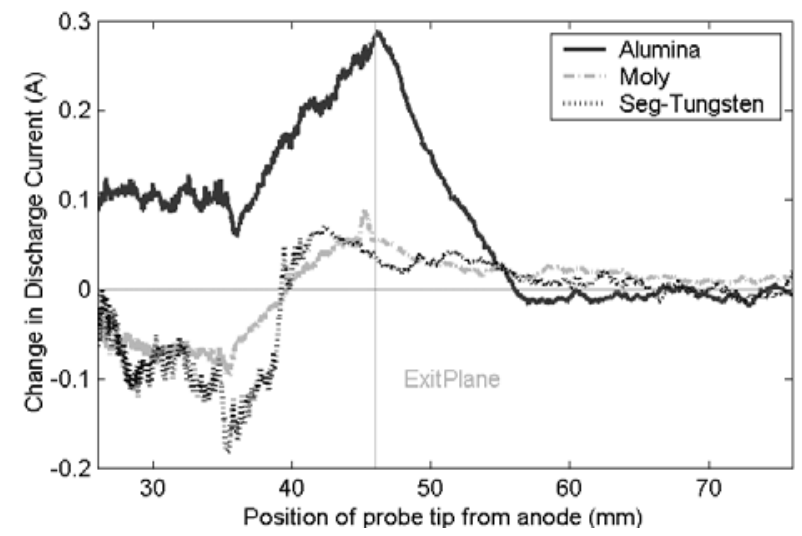

Figure 8 


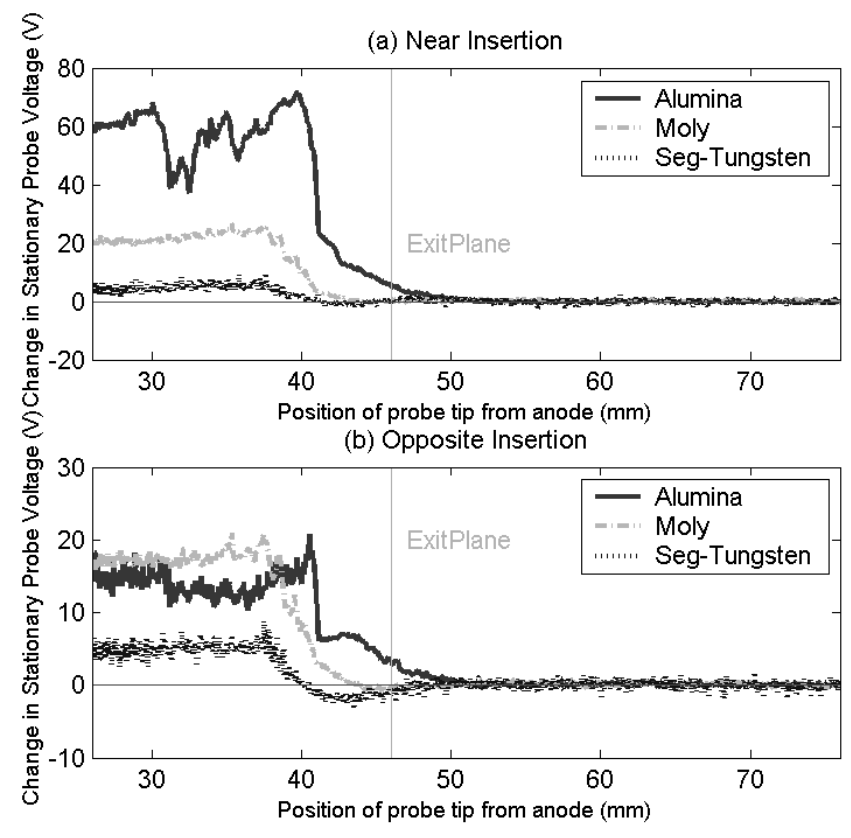

Figure 9 


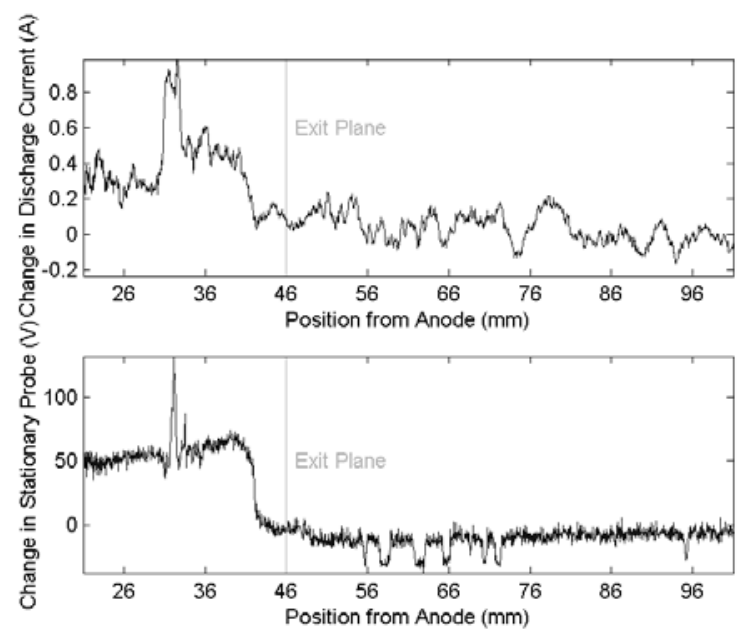

Figure 10 


\section{External Distribution}

Plasma Research Laboratory, Australian National University, Australia

Professor I.R. Jones, Flinders University, Australia

Professor João Canalle, Instituto de Fisica DEQ/IF - UERJ, Brazil

Mr. Gerson O. Ludwig, Instituto Nacional de Pesquisas, Brazil

Dr. P.H. Sakanaka, Instituto Fisica, Brazil

The Librarian, Culham Laboratory, England

Mrs. S.A. Hutchinson, JET Library, England

Professor M.N. Bussac, Ecole Polytechnique, France

Librarian, Max-Planck-Institut für Plasmaphysik, Germany

Jolan Moldvai, Reports Library, Hungarian Academy of Sciences, Central Research Institute for Physics, Hungary

Dr. P. Kaw, Institute for Plasma Research, India

Ms. P.J. Pathak, Librarian, Institute for Plasma Research, India

Ms. Clelia De Palo, Associazione EURATOM-ENEA, Italy

Dr. G. Grosso, Instituto di Fisica del Plasma, Italy

Librarian, Naka Fusion Research Establishment, JAERI, Japan

Library, Laboratory for Complex Energy Processes, Institute for Advanced Study, Kyoto University, Japan

Research Information Center, National Institute for Fusion Science, Japan

Dr. O. Mitarai, Kyushu Tokai University, Japan

Dr. Jiangang Li, Institute of Plasma Physics, Chinese Academy of Sciences, People's Republic of China

Professor Yuping Huo, School of Physical Science and Technology, People's Republic of China

Library, Academia Sinica, Institute of Plasma Physics, People's Republic of China

Librarian, Institute of Physics, Chinese Academy of Sciences, People's Republic of China

Dr. S. Mirnov, TRINITI, Troitsk, Russian Federation, Russia

Dr. V.S. Strelkov, Kurchatov Institute, Russian Federation, Russia

Professor Peter Lukac, Katedra Fyziky Plazmy MFF UK, Mlynska dolina F-2, Komenskeho Univerzita, SK-842 15 Bratislava, Slovakia

Dr. G.S. Lee, Korea Basic Science Institute, South Korea

Institute for Plasma Research, University of Maryland, USA

Librarian, Fusion Energy Division, Oak Ridge National Laboratory, USA

Librarian, Institute of Fusion Studies, University of Texas, USA

Librarian, Magnetic Fusion Program, Lawrence Livermore National Laboratory, USA

Library, General Atomics, USA

Plasma Physics Group, Fusion Energy Research Program, University of California at San Diego, USA

Plasma Physics Library, Columbia University, USA

Alkesh Punjabi, Center for Fusion Research and Training, Hampton University, USA

Dr. W.M. Stacey, Fusion Research Center, Georgia Institute of Technology, USA

Dr. John Willis, U.S. Department of Energy, Office of Fusion Energy Sciences, USA

Mr. Paul H. Wright, Indianapolis, Indiana, USA 
The Princeton Plasma Physics Laboratory is operated by Princeton University under contract with the U.S. Department of Energy.

\author{
Information Services \\ Princeton Plasma Physics Laboratory \\ P.O. Box 451 \\ Princeton, NJ 08543
}

Phone: 609-243-2750

Fax: 609-243-2751

e-mail: pppl_info@pppl.gov

Internet Address: http://www.pppl.gov 